\title{
Brazilian brain experts plan research village
}

Hannah Hoag

Three expatriate Brazilian neuroscientists have launched a bid to build a research centre in the northern coastal city of Natal in Brazil. According to their plans, the institute will focus on neuroscience, and will include a mental-health clinic and a school for underprivileged children.

The move is well timed - Brazil's new president, Luiz Inácio Lula da Silva, has pledged to boost the country's research budget and promote science in areas away from the traditional centres of excellence in Rio de Janeiro and São Paulo in the south (see News Feature, page 379). But those involved in the bid admit that it will be difficult to raise the US\$20 million needed to set up the centre.

The three neuroscientists behind the plan are Miguel Nicolelis and Sidarta Ribeiro of Duke University in Durham, North Carolina, and Claudio Mello of the Oregon Health and Science University in Portland. They say that the new institute will employ expertise in molecular and cellular biology and electrophysiology in an attempt to understand the basic mechanisms that control cellular circuits within the brain.

The plans have already gained some eminent backers. Nicolelis says that Nobel laureate Torsten Wiesel, president emeritus of Rockefeller University in New York, has
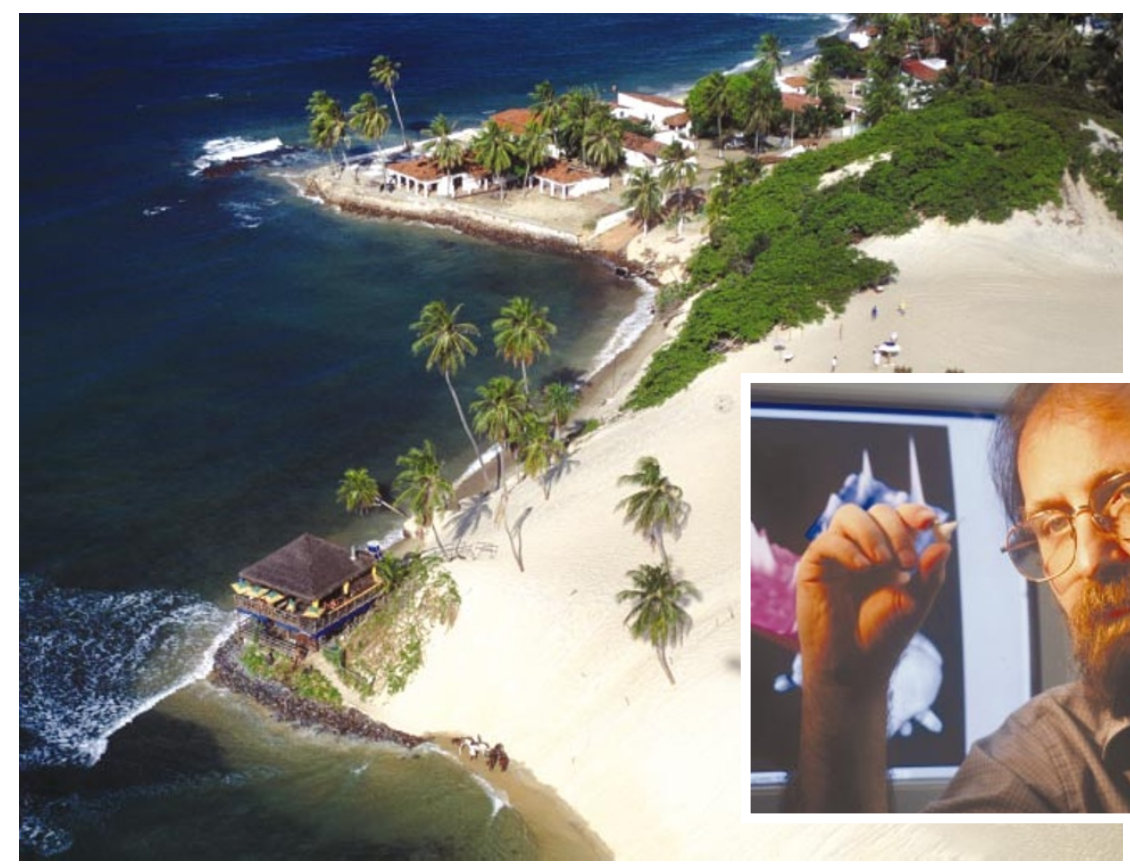

Life's a beach: Miguel Nicolelis (inset) hopes to build a neuroscience campus at Natal in north Brazil.

agreed to be a trustee. And Jon Kaas, a neuroscientist at Vanderbilt University in Nashville, Tennessee, who has collaborated with Brazilian researchers for two decades, will also join the board. "There is a lot of very

\section{Spiralling costs dog comet mission}

\section{Declan Butler, Paris}

Europe's troubled Rosetta comet mission has a new target, but it is not out of the woods yet - a lack of funds still threatens the project.

The Rosetta craft, which is designed to land on a comet, was scheduled for lift-off in January this year, but the launch was postponed as a result of technical problems with the new class of Ariane rockets used by the European Space Agency (ESA). The delay meant that the probe missed the window to reach its original target, the comet Wirtanen (see Nature 421, 301-302; 2003).

At a meeting of ESA's science committee last week, officials confirmed that the new target will be the comet ChuryumovGerasimenko. But before the launch, which will take place on 26 February 2004 on a standard Ariane 5 rocket, extra money must be raised. The cost of storing the satellite and redesigning the mission will be some $€ 70$ million (US\$82 million).

David Southwood, ESA's head of science, says that nobody wants Rosetta to be cancelled, especially as most of its costs have already been paid. But ESA's science programme is facing a cashflow crisis. Problems with the Ariane rockets have added to the costs of several planned missions, and a downturn in the commercial space market means that ESA's industrial partners are now demanding more money up front for their involvement in collaborative projects.

Last week's meeting heard that ESA's science budget is facing an overrun of $€ 140$ million this year, and this is set to increase in the following two years. To launch Rosetta, the science programme will need a loan from ESA's governing body.

ESA has also had to pay out more than $€ 70$ million to support scientists building instruments for its Herschel infrared space observatory and for its Planck mission, which will study cosmic microwaves. Both projects are slated to launch together in 2007. ESA traditionally pays spacecraft and launch costs, with member states footing the bill for instruments. But the agency is increasingly having to pay for instruments, and officials say that future payloads will be subject to contracts requiring member states to commit to full funding for the project's duration. good talent in Brazil, but they have had a hard time getting research time and research facilities," says Kaas.

Additional facilities such as the mentalhealth centre and the children's school will dot the institute's campus. "There will be a large social programme linked to the scientific endeavour," says Nicolelis. The school, for example, will enrol over 300 underprivileged toddlers and provide them with an education rich in science, language and arts until their late teens.

But funding the institute is likely to be a struggle. The neuroscientists plan to collect money through a non-profit organization which will be named after the Brazilian aviation pioneer, Alberto Santos-Dumont. Nicolelis estimates that they will need over $\$ 20$ million to build the institute and set up an endowment. But he has received only $\$ 50,000$ in pledges from private donors, and he concedes that most of this will be used to finance an international symposium on neuroscience scheduled to take place in Natal in March 2004

Brazilian politicians, including science minister Roberto Amaral and education minister Cristovam Buarque, have backed the project. But officials at the Brazilian government say that their contribution will primarily be a donation of a 150 acres of land. The majority of funding for Brazilian science currently comes from state and federal government, raising questions about how much money Nicolelis and his colleagues will be able to raise from private sources in the country. 